\title{
VALOR PREDITIVO DA EXPRESSÃO DOS ANTICORPOS ANTIFATOR VIII NO CARCINOMA EPIDERMÓIDE DO ESÔFAGO
}

\section{Predictive value of antifactor VIII antibody expression in squamous cell carcino- ma of the esophagus}

\author{
Sebastião Gonzaga BARBOSA-NETO ${ }^{1}$, Ronaldo Mafia CUENCA $^{1}$, Jurandir Marcondes RIBAS-FILHO ${ }^{2}$, \\ Osvaldo MALAFAIA ${ }^{2}$, Danielle Duck SCHULTZ ${ }^{2}$, Paulo Afonso Nunes NASSIF ${ }^{2}$, \\ Eduardo BATISTELLA ${ }^{2}$, Letícia Elizabeth Augustin CZECZKO $^{2}$
}

ABCDDV/571

Barbosa-Neto SG, Cuenca RM, Ribas-Filho JM, Malafaia O, Schultz DD, Nassif PAN, Batistella E, Czeczko LEA. Valor preditivo da expressão dos anticorpos Antifator VIII no carcinoma epidermóide do esôfago. ABCD Arq Bras Cir Dig 2007;20(4):261-5

RESUMO - Racional - O carcinoma epidermóide do esôfago apresenta alta mortalidade, baixo índice de diagnóstico precoce e altos custos nos tratamentos, com resultados freqüentemente desapontadores e prognóstico sombrio. O melhor entendimento das técnicas de biologia molecular com citofotometria de imagem, permitiu avançar no conhecimento das alterações na expressão das proteínas desse câncer. Objetivos - Quantificar a expressão das proteínas envolvidas na angiogênese e correlacioná-las com variáveis clínico-patológicas. Métodos - Com o uso da técnica de imunoistoquímica, citofotometria de imagem pelo sistema SAMBA, foram analisadas 29 amostras de carcinoma epidermóide do esôfago incluídas em blocos de parafina. Critérios clínicos como idade, sexo e histopatológicos do grau de diferenciação tumoral, tamanho e localização do tumor foram analisados. Os parâmetros analisados foram o índice de marcagem e a densidade óptica. O marcador utilizado foi o anticorpo anti-Fator VIII. Resultados - Foi possível verificar que as expressões médias do marcador no índice de marcagem foram maiores que as da densidade óptica. Fator VIII apresentou leituras homogêneas. O índice de marcagem foi de $80,17+/-10,40$ com $\mathrm{P}=0,073$ e a densidade óptica $51,25+/-11,02$ com $\mathrm{P}=0,245$. Conclusão - A análise quantificação da expressão das proteínas envolvidas na angiogênese permite definir subgrupos de acordo com a diferenciação do carcinoma, estágio tumoral, tamanho e localização do tumor, porém não associa-se com o sexo e a idade dos pacientes, e a densidade óptica do Fator VIII não tem expressão significativa em nenhum dos subgrupos analisados.

DESCRITORES - Carcinoma epidermóide de esôfago. Imunoistoquímica. Citofotometria de imagem. Fator VIII.

\section{INTRODUÇÃO}

O câncer esofágico é sexta causa de morte por câncer, ocupando o $8^{\circ}$ lugar mundial em incidência, com distribuição sócio-geográfica muito heterogênea dentro até de um mesmo país. Oitenta por cento das mortes ocorrem em países em desenvolvimento, que apresentam maior prevalência do carcinoma epidermóide de esôfago (CEE), enquanto que o adenocarcinoma (AC) é mais freqüente quando associado à doença do refluxo gastroesofágico com metaplasia intestinal. O Brasil está entre os dez países mais incidentes

O câncer de esôfago está associado freqüentemente ao alto consumo de bebidas alcoólicas e de produtos derivados do tabaco. A agressão direta ao DNA celular tem sido atribuída a alguns tipos de vírus no processo da carcinogênese do carcinoma de células escamosas. O Papiloma Vírus Humano (HPV) tem sido estudado quanto ao possível envolvimento nesse processo ${ }^{6}$.

Na região sul do Brasil e países vizinhos há forte correlação com a ingestão do mate quente.

Trabalho realizado na ${ }^{1}$ União Educacional do Planalto Central - UNIPLAC - Brasília, DF e ${ }^{2}$ Hospital Universitário Evangélico de Curitiba - HUEC - Curitiba, PR, Brasil.

Endereço para correspondência: Ronaldo Mafia Cuenca, e-mail: rmcuenca@uol.com.br
O prognóstico do câncer de esôfago é muito ruim. Por ser neoplasia muito agressiva, com características de invasão precoce na submucosa e ocorrência de metástases, tem sobrevida em cinco anos de 10 a $20 \%$, a despeito do tratamento instituído ${ }^{4}$. Quando se consegue tratar doentes com diagnóstico precoce, a sobrevida, em cinco anos, pode chegar até $100 \%{ }^{1}$. Portanto, o diagnóstico precoce nos doentes assintomáticos e com fatores de risco evidentes pode elevar sua sobrevida.

Muitas das proteínas de genes podem ser detectadas por técnicas de imunoistoquímica, servindo como marcadores de lesões com alto risco de progressão para doença maligna. A expressão da proteína Fator VIII é importante por dois motivos: primeiro, porque a sua presença geralmente indica tumores mais agressivos, com menor sobrevida; segundo, porque ela é importante no prognóstico do tumor. $\mathrm{O}$ conceito de que o crescimento tumoral é angiogênicodependente é hoje aceito, com mais de 2.500 trabalhos científicos mostrando a angiogênese associada ao crescimento tumoral, e de forma unânime que, cada incremento do crescimento tumoral requer aumento correspondente do crescimento vascular.

A utilização do marcador para Fator VIII e, especialmente, sua combinação com outros marcadores, pode contribuir para prognosticar a agressividade do CEE. A 
imunoistoquímica com anticorpo para o antígeno Fator VIII está bem estabelecida, porém isoladamente não permite a análise de conteúdo citoplasmático e da atividade proliferativa do DNA. Também não identifica o padrão nuclear aneuplóide, onde as características de lesão mais agressiva são evidenciadas. Uma das limitações da imunoistoquímica tradicional é a sua dependência de análise subjetiva pelo patologista.

Essas limitações poderiam ser superadas com a associação de métodos que possibilitem a análise individual do núcleo celular, como a citometria de fluxo. Com o desenvolvimento atual da tecnologia de citometria de imagem ou citofotometria, associada à imunoistoquímica, é possível a análise da atividade proliferativa do DNA, célula por célula, estabelecendo taxas de ploidia e também estudo do proteoma citoplasmático. A informatização através de sistemas computadorizados é o meio ideal para ter-se dados numéricos que representem melhor a situação histológica. Assim, este estudo pretende contribuir com o avanço da pesquisa no câncer esofágico determinando a expressão do anticorpo anti-Fator VIII obtida pela citofotometria de imagem e se há correlação com o estágio tumoral, tamanho e localização do tumor, sexo e idade dos pacientes.

\section{MÉTODOS}

A amostra constou de 30 blocos de parafina com CEE, preparadas a partir de peças cirúrgicas produto de esofagectomias. Esses blocos foram provenientes de pacientes registrados, diagnosticados e pertencentes aos arquivos dos serviços de anatomia patológica do Hospital Regional do Gama - Brasília-DF (8); Hospital das Forças Armadas - Brasília-DF (5); Hospital Brasília -BrasíliaDF (2) e Hospital São Marcos -Teresina-PI (15).

Visando melhor uniformizar a amostra, foram estabelecidos critérios de inclusão e exclusão

Os de Inclusão foram: pacientes portadores de CEE, confirmados por histopatologia; material biológico proveniente de peça cirúrgica; amostra tumoral representativa no bloco de parafina para que pudessem ser obtidos pelo menos três cortes, material de boa qualidade e em bom estado de preservação. Os de exclusão foram: diagnóstico não confirmado; pacientes com tratamentos prévios (quimioterapia e/ou radioterapia) e prontuários de pacientes não qualificados, com dados incompletos.

De cada paciente foi extraído um conjunto de informações classificadas da seguinte maneira: dados clínicos (idade $>55$ ou $<55$ anos) e sexo; dados histológicos (grau de diferenciação tumoral segundo a OMS em bem diferenciado - G1; moderadamente diferenciado - G2; pouco diferenciado - G3; tamanho tumoral $(-<3 \mathrm{~cm} \mathrm{->}$ $3 \mathrm{~cm}$ ); localização do tumor (esôfago torácico segmentos superior, médio e inferior) e estadiamento TNM.

As amostras foram re-analisadas para confirmação diagnóstica pelo método habitual de HE. Na imunoistoquímica a expressão do Fator VIII foi obtida através do método da streptoavidina-biotina-peroxidase com o anticorpo Von Willebrand Factor-Vwf policlonal de coelho, anti-humano DAKO, contra o antígeno Fator VIII.

A análise das células imunopositivas para o anticorpo contra Fator VIII foi realizada utilizando a citofotometria de imagem pelo método SAMBA (Système D'analyse Microscopique a Balayage Automatique ou Sistema de Análise Microscópica de Busca Automática) em campos definidos como hot spots em microscópio óptico. A captura das imagens foi feita por meio de câmera colorida, capaz de padronizar as cores verdes, azuis e vermelhas (sistema RGB "red, green, blue"), de forma que trabalhe com o mesmo nível de captação determinado. A imagem captada por fotodiodos, foi transformada em pontos de imagem (pixel), com área equivalente a $0.16 \mu \mathrm{m}^{2}$ por ponto-imagem e enviada ao computador. Na interprestação dos achados foi utilizado o software Imunno 4.00. As imagens analógicas, tais como são percebidas ao microscópio, foram captadas através da câmera e enviadas ao computador, que utilizando o software Imunno, digitalizou-as transformando-as em imagens numéricas. Este processo conferiu um valor para cada ponto-imagem (pixel). A luz absorvida pelo tecido em cada segmento foi quantificada. Esta quantificação foi expressa através de uma escala de variações de níveis de cinza que vai do 0 (preto) a 255 (branco). Este processo correspondeu a numerização da imagem envolvendo duas etapas: geração da matriz em tons de cinza e transformação dela em matriz numérica binária.

Para leitura, realizou-se o rastreamento dos campos visuais para localização dos "hot spot" e o procedimento foi realizado em sentido de barra grega. O total de superfícies examinadas variou de 60.000 a 120.000 um2. O tempo de leitura para cada lâmina foi de aproximadamente 40 minutos. .4 Parâmetros analisados pelo sistema samba 4000 .

\section{Parâmetros analisados}

O software Immuno 4.00 analisou duas variáveis para caracterizar quantitativamente, as expressões dos marcadores: índice de marcagem, densidade óptica média.

O índice de marcagem (IM), descreve o percentual de área tecidual especificamente marcado pela prova histoquímica. A densidade óptica (DO) denota a intensidade de coloração.

A padronização do sistema para análise microscópica computadorizada é realizada por uma lâmina considerada controle-negativo, na qual o marcador contra Fator VIII é omitido, e os parâmetros acima descritos são analisados.

Os testes para análise e estatística foram realizados pelo mesmo software e pelo Statistical Package for Social Science (SPSS) 11.5 for Windows. Os resultados do estudo em relação às variáveis quantitativas foram expressos por médias, medianas, valores mínimos, valores máximos e desvios padrões. Para as variáveis categóricas, eles foram expressos por freqüências e percentuais. A condição de normalidade das variáveis quantitativas foi investigada usando-se o teste de Shapiro-Wilks. Valores de P $<0,05$ foram considerados com significância estatística. 


\section{RESULTADOS}

Um bloco da amostra foi excluído do total de 30, pelo controle de qualidade. Portanto, os resultados estão expressos para 29 casos

As características da amostra (Tabela 1 e Figura 1) foram: maior concentração tumoral nas idades acima de 55 anos, no sexo masculino, amostras com tamanho tumoral $>3$ e nos segmentos médio e inferior.

A Tabela 2 mostra que os moderamente diferenciados (G2), e o estágio III (TNM) concentrou o maior número de casos.

TABELA 1 - Características clínicas e patológicas da amostragem utilizada

\begin{tabular}{lccc}
\hline Dados & & $\mathbf{n}$ & $\%$ \\
\hline Idade & $<41-55 \mathrm{a}$ & 08 & $(26,6)$ \\
& $>55-69 \mathrm{a}$ & 22 & $(73,3)$ \\
Sexo & Masculino & 25 & $(83,4)$ \\
& Feminino & 05 & $(16,6)$ \\
Tamanho tumoral & $<3 \mathrm{~cm}$ & 09 & $(30,0)$ \\
& $>3 \mathrm{~cm}$ & 21 & $(70,0)$ \\
Localização do tumor no & superior & 01 & $(3,3)$ \\
esôfago torácico & médio & 13 & $(43,3)$ \\
& inferior & 16 & $(53,3)$ \\
\hline
\end{tabular}

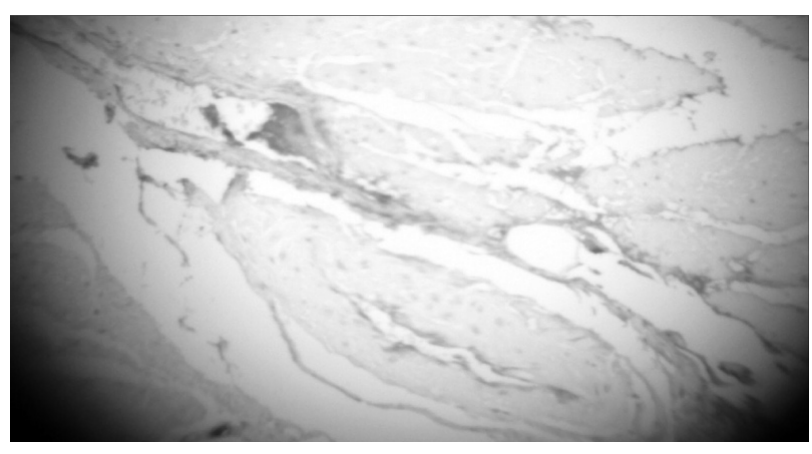

FIGURA 1 - Fotomicrografia de corte histológico de amostra de carcinoma epidermóide de esôfago com anticorpo anti-Fator VIII (100100/400x)

A análise estatística foi aplicada nos resultados interpretados pelo SAMBA, da expressão dos marcadores e nos resultados correlacionados com os do subgrupo (diferenciação, estágio tumoral, tamanho e localização dos tumores).

É possível verificar na Tabela 3 que as expressões médias no índice de marcagem são maiores que as verificadas pela densidade óptica.

O marcador Fator VIII apresentou leituras homogêneas devido à menor variabilidade representada pelo desviopadrão e a amplitude dos dados. A única correlação que mostrou significância estatística foi entre o IM e DO da expressão do Fator VIII, indicando que as diferentes leituras do mesmo marcador trazem resultados semelhantes, ou seja, relacionados.
TABELA 2 - Características histopatológicas e classificação segundo TNM das amostras

\begin{tabular}{lllc}
\hline Dados & & n & \% \\
\hline Bem diferenciado & $(\mathrm{G} 1)$ & 07 & $(23,3)$ \\
$\begin{array}{l}\text { Moderamente diferenciado }(\mathrm{G} 2) \\
\text { Pouco diferenciado }\end{array}(\mathrm{G} 3)$ & 19 & $(63,3)$ \\
Estágio II (TNM) & & 04 & $(13,3)$ \\
pt2 pNx pMx & 02 & $(6,6)$ \\
pT2 pN1a pMx & 01 & $(3,3)$ \\
Estágio III (TNM) & 01 & $(3,3)$ \\
pT3 pNx pMx & 28 & $(93,3)$ \\
pT3 pN1a pMx & & 13 & $(43,3)$ \\
pT3 pN1b pMx & & 11 & $(36,6)$ \\
\hline
\end{tabular}

TABELA 3 - Resultados de valores média, desvios-padrão e valor de $\mathrm{P}$ em relação a freqüência do índice de marcagem, densidade óptica do Fator VIII

\begin{tabular}{lccc}
\hline Variavel & $\mathbf{n}$ & Média $\pm \mathbf{D P}$ & Valor de $\mathbf{P}$ \\
\hline IM do Fator VIII & 28 & $80,17+/-10,40$ & 0,073 \\
DO do Fator VIII & 28 & $51,25+/-11,02$ & 0,245 \\
\hline
\end{tabular}

\section{Correlação entre a diferenciação do carcinoma e a expressão do marcador}

Testou-se a hipótese nula de que os resultados são iguais para carcinoma epidermóide pouco diferenciado, moderadamente diferenciado e bem diferenciado, versus a hipótese alternativa de resultados diferentes. Na Tabela 4 são apresentadas às estatísticas descritivas (média, mediana, valor mínimo, valor máximo e desvio padrão) e os valores de $\mathrm{p}$ dos testes estatísticos (Kruskal-Wallis).

Os resultados dos testes estatísticos indicaram que não houve diferença entre os parâmetros.

TABELA 4 - Valores da média, desvio-padrão e valor de P do Fator VIII em diferentes níveis histológicos

\begin{tabular}{|c|c|c|c|c|c|}
\hline Variavel & Carcinoma & n & Média & Desvio- padrão & Valor de P \\
\hline \multirow{3}{*}{ Fator VIII IM } & Pouco & 3 & 79,44 & 3,79 & \multirow{3}{*}{0,747} \\
\hline & Moderado & 20 & 81,14 & 10,26 & \\
\hline & Bem & 5 & 76,76 & 14,27 & \\
\hline \multirow{3}{*}{$\begin{array}{c}\text { Fator VIII } \\
\text { DO }\end{array}$} & Pouco & 3 & 45,50 & 2,97 & \multirow{3}{*}{0,519} \\
\hline & Moderado & 20 & 52,71 & 11,59 & \\
\hline & Bem & 5 & 48,88 & 11,61 & \\
\hline
\end{tabular}

Para identificar diferenças no subgrupo histológico, os testes mostraram que existe diferença significativa $(\mathrm{P}=0,044)$ entre carcinomas pouco diferenciados e os moderadamente diferenciados. Na comparação de carcinomas pouco diferenciados com bem diferenciados, o resultado indicou que não existe diferença significativa $(\mathrm{P}=0,881)$, o mesmo ocorrendo na comparação de carcinomas moderadamente diferenciados com os bem diferenciados $(\mathrm{P}=0,074)$. 


\section{Correlação entre o estágio do carcinoma e o tamanho tumoral com a expressão do marcador}

TABELA 5 - Valores da média, desvio-padrão e valor de P, das expressões do marcador comparadas com o estadiamento das amostras

\begin{tabular}{ccccccc}
\hline Variavel & $\begin{array}{c}\text { Estágio do } \\
\text { carcinoma }\end{array}$ & $\mathbf{n}$ & Média & Desvio- padrão & Valor de P \\
\hline \multirow{2}{*}{ Fator VIII IM } & IIA IIB & 14 & 79,74 & 11,15 & \multirow{2}{*}{0,832} \\
& III & 14 & 80,60 & 10,00 & \\
\cline { 1 - 5 } Fator VIII & IIA IIB & 14 & 51,61 & 12,47 & \multirow{2}{*}{0,866} \\
\cline { 2 - 5 } DO & \multicolumn{2}{c}{ IIA IIB } & 14 & 50,89 & 9,82 & \\
IM=indice de marcagem & DO=densidade óptica & &
\end{tabular}

Para IM e DO do Fator VIII os resultados dos testes estatísticos indicaram que não existe diferença significativa entre os estágios IIA e IIB do estágio III.

Quanto ao tamanho do tumor testou-se a hipótese nula de que os resultados são iguais para tumores com tamanho $<3$ e tumores com tamanho $>3$, versus a alternativa de resultados diferentes.

Para cada um dos marcadores, Na tabela 8 abaixo são apresentados as médias, desvio padrão e os valores de $\mathrm{p}$ dos testes estatísticos:

Para os valores do IM e DO os resultados dos testes estatísticos indicaram que não existe diferença significativa entre estas expressões para tumores com tamanho $<3$ e com tamanho $>3$.

TABELA 6 - Tamanho tumoral, valores médios, desvios-padrão e valores de P para as expressões do Fator VIII

\begin{tabular}{cccccc}
\hline Variavel & Tamanho & $\mathbf{n}$ & Média & Desvio- padrão & Valor de P \\
\hline \multirow{2}{*}{ Fator VIII IM } & $<3$ & 9 & 81,38 & 10,98 & \multirow{2}{*}{0,743} \\
\cline { 1 - 5 } & $>3$ & 18 & 79,26 & 10,56 & \\
\multirow{2}{*}{$\begin{array}{c}\text { Fator VIII } \\
\text { DO }\end{array}$} & $<3$ & 9 & 55,02 & 14,31 & \multirow{2}{*}{0,495} \\
\cline { 2 - 5 } & $>3$ & 18 & 49,54 & 9,24 & \\
IM=indice de marcagem & DO=densidade optica & &
\end{tabular}

Comparação entre a localização do tumor, a idade e o sexo e a expressão do marcador

Para tumores com localização inferior ou inferior-médio e tumores com localização média ou superior são apresentados os valores da média, desvio-padrão e os de P.

$\mathrm{O}$ resultado do teste estatístico, indicou que há diferença significativa entre tumores com localização inferior ou inferior-médio e os com localização média ou superior (Tabela 7) quanto à expressão.

Já com a idade, testou-se a hipótese nula de ausência de correlação entre a idade e as expressões do marcador, versus a hipótese alternativa de existência de correlação. Os resultados são apresentados na Tabela.

Os resultados indicam que não há correlação significativa entre idade e a expressão do marcador, testando-se a hipótese nula de que os resultados são iguais para pacientes com idade até 55 anos e para os com mais do que 55, versus a hipótese alternativa de resultados diferentes (Tabelas 8 e 9)
TABELA 7- Médias, desvio-padrão e valores de $\mathrm{P}$ das expressões do marcador comparados com a localização tumoral

\begin{tabular}{cccccc}
\hline Variavel & $\begin{array}{c}\text { Localização no esôfago } \\
\text { torácico }\end{array}$ & $\mathbf{n}$ & Média & $\begin{array}{c}\text { Desvio- } \\
\text { padrão }\end{array}$ & $\begin{array}{c}\text { Valor } \\
\text { de P }\end{array}$ \\
\hline \multirow{2}{*}{ Fator VIII IM } & Inferior ou inferior-médio & 14 & 76,29 & 9,73 & \multirow{2}{*}{0,046} \\
\cline { 2 - 5 } & Médio ou superior & 14 & 84,05 & 9,88 & \\
\cline { 1 - 5 } Fator VIII DO & Inferior ou inferior-médio & 14 & 47,08 & 10,31 & \multirow{2}{*}{0,043} \\
\cline { 2 - 5 } & Médio ou superior & 14 & 55,43 & 10,42 & \\
IM=indice de marcagem DO=densidade óptica & & &
\end{tabular}

TABELA 8 - Coeficientes de correlação entre idade e o marcador

\begin{tabular}{ccc}
\hline Marcador & Coeficiente de correlação & Valor de $\mathbf{P}$ \\
\hline Fator VIII IM & $-0,223$ & 0,273 \\
Fator VIII DO & $-0,065$ & 0,751 \\
IM=indice de marcagem & DO=densidade óptica &
\end{tabular}

TABELA 9 - Valores da média, desvio-padrão e os valores de $\mathrm{P}$ da correlação entre Fator VIII com a idade dos pacientes

\begin{tabular}{lccccc}
\hline Variável & Idade (anos) & $\mathbf{n}$ & Média & Desvio-padrão & Valor de P \\
\hline \multirow{2}{*}{ Fator VIII IM } & Até 55 & 8 & 86,08 & 5,65 & \multirow{2}{*}{0,089} \\
& Mais que 55 & 20 & 77,81 & 11,02 & \\
\multirow{2}{*}{ Fator VIII DO } & Até 55 & 8 & 54,06 & 7,99 & 0,237 \\
& Mais que 55 & 20 & 50,13 & 12,02 & \\
IM=indice de marcagem DO=densidade óptica & &
\end{tabular}

Foram realizados outros cortes comparativos abaixo de 50 anos e acima, abaixo e acima de 65 anos e os resultados também não foram estatisticamente significativos.

Na Tabela 10 são apresentados a média, desvio-padrão e os valores de $\mathrm{P}$ dos testes estatísticos em relação ao sexo do paciente.

Os resultados indicaram que não existe diferença significativa entre tumores de pacientes do sexo masculino e feminino.

TABELA 10 - Valores da média, desvio-padrão, valor de P, da correlação entre sexo e a expressão do marcador

\begin{tabular}{|c|c|c|c|c|c|}
\hline Variável & Sexo & $\mathbf{n}$ & Média & Desvio-padrão & Valor de $P$ \\
\hline \multirow{2}{*}{ Fator VIII IM } & Masculino & 24 & 81,80 & 9,73 & \multirow{2}{*}{0,050} \\
\hline & Feminino & 4 & 70,41 & 9,96 & \\
\hline \multirow{2}{*}{ Fator VIII DO } & Masculino & 24 & 51,50 & 11,43 & \multirow{2}{*}{0,776} \\
\hline & Feminino & 4 & 49,73 & 9,36 & \\
\hline
\end{tabular}

\section{DISCUSSÃO}

Recente metanálise ${ }^{2}$ estabeleceu que pacientes que não respondem às terapias coadjuvantes apresentam prognóstico inferior aos tratados somente cirurgicamente e, assim ressalta a necessidade de marcadores preditivos para aumentar o número de respostas prognósticas as terapias auxiliares. Uma variedade de técnicas têm sido empregada para investigar estes marcadores. A mais comum, a expressão protéica, tem sido avaliada pela imunoístoquimica, 
entretanto é método subjetivo e semi-quantitativo que é limitado pela sensibilidade do anticorpo monoclonal e pelos tecidos fixados.

Técnica mais sofisticada têm sido empregadas e desenvolvidas: expressão gênica, micro-dissecação do tumor (limitada por exigir biópsia dos tecidos), identificação de marcadores preditivos e prognósticos, avaliação do polimorfismo genômico e finalmente, citofotometria de imagem (SAMBA).

A associação de três marcadores e sua correlação foi pesquisada por diversos autores, mas na literatura Ki-67 e Fator VIII e citometria de imagem em esôfago somente um trabalho ${ }^{3}$ existe. Os resultados sugeriram que a associação entre o índice de marcagem da expressão dThdPase com os do Fator VIII poderá representar fator de prognóstico do CEE.

Embora os autores acima não tenham estudado os dados da densidade óptica para o fator VIII, o presente trabalho identificou associação linear desta expressão com as expressões do índice de marcagem $(\mathrm{P}=0,001)$, e mostra que as duas marcações IM e DO para o fator VIII são relevantes quando lidas em conjunto.
A maioria dos estudos recentes mostra que a contagem dos micro-vasos pelos marcadores angiogênicos, como o anti-Fator VIII em expressões independentes, nem sempre mostra conotação preditiva. Autores ${ }^{7}$ mostraram que a contagem dos micro-vasos pelo Fator VIII foi significante como prognóstico, quando associada aos sinais clínicos e histopatológicos.

Da mesma forma, neste estudo e em concordância com a literatura, pacientes do sexo feminino e do sexo masculino, e faixas de idade acima e abaixo de 55 anos tiveram níveis de expressões do anticorpo anti-Fator VIII similares, não significativos.

\section{CONCLUSÃO}

A análise da quantificação da expressão das proteínas envolvidas na angiogênese permite definir subgrupos de acordo com a diferenciação do carcinoma, estágio tumoral, tamanho e localização do tumor, porém não associa-se com o sexo e a idade dos pacientes, e a densidade óptica do Fator VIII não tem expressão significativa em nenhum dos subgrupos analisados.

Barbosa-Neto SG, Cuenca RM, Ribas-Filho JM, Malafaia O, Schultz DD, Nassif PAN, Batistella E, Czeczko LEA. Predictive value of antifactor VIII antibody expression in squamous cell carcinoma of the esophagus. ABCD Arq Bras Cir Dig 2007;20(4):261-5.

ABSTRACT - Background - Squamous cell carcinoma of the esophagus exhibits high mortality rate, rare precocious diagnosis, and expensive treatments, presenting frequently disappointed results and poor prognosis. The better understanding about Molecular Biology techniques using cytophotometric imaging allowed to progress knowledge on protein expression alterations for such neoplasia. Aim - To quantify protein expression implicated in the angiogenesis process and correlate to clinical-pathological features. Methods - Using immunohistochemistry procedure, cytophotometric imaging by SAMBA, 29 sampled-tissue embedded in paraffin blocks of squamous cell carcinoma of the esophagus were analyzed. Clinical criteria, such as age and gender, as well as histophatological criteria, such as differentiated grade features, size and tumor location, were considered. Parameters evaluated were labeling index and optical density. The marker used in the present study was antifactor VIII. Results - Verification on the expression of the marker in labeling index parameter was greater than optical density. Factor VIII presented homogeneous reading out. Labeling index was $80,17+10,40(\mathrm{p}=0,073)$ and optical density $51,25+11,02(\mathrm{p}=0,245)$. Conclusion - Protein expression reading analysis involved in angiogenesis process allows to define subgroups according to differentiated grade carcinoma, tumoral staging, size and tumor localization, although it does not allow association with gender and patient age. Optical density for factor VIII does not have statistical significant expression in any subgroup evaluated.

HEADINGS - Carcinoma, squamous cell. Immunohistochemistry. Cytophotometric imaging. Factor VIII.

\section{REFERÊNCIAS}

1. Endo M, Takeshita K, Yoshida M. How can we diagnose early stage of esophageal cancer? Endoscopy, 1986;18 Suppl. 3:11.

2. Greer SE, Goodney PP, Sutton JE, Birkmeyer JD. Neoadjuvant chemoradiotherapy for esophageal carcinoma: a meta-analysis. Surgery. 2005 Feb; 137(2):178-9.

3. Koide N, Nishio A, Kono T, Yazawa K, Igarashi J, Watanabe H, Nimura Y, Hanazaki K, Adachi W, Amano J. Histochemical study of vascular endothelial growth factor in squamous cell carcinoma of the esophagus. Hepatogastroenterology. 1999, Mar-Apr;46(26):952-8.

4. Shiozaki H, Tahara H, Kobayashi K, Yano H, Tamura S, Imamoto H, Yano Y, Oku K, Miyata M, Nishiyama K, Kubo K, Mori T. Endoscopic screening of early esophageal cancer with the lugol dye method in patients with head and neck cancers. Cancer, 1990; 66:2068.
5. Sugimachi K, Ohno S, Matsuda H, Mori M, Kuwano H. Lugol-combined endoscopic detection of minute malignant lesions of the thoracic esophagus. Ann Surg 1988; 208:179-83.

6. Sugiyama M, Uk Bhawal T, Dohmen O, Shigehiro S. Detection of Human papilomavirus-16 and HPV-18 in normal, dysplastic, and malignant oral epithelium. Med Oral Pathol 2003; 95: 594-600.

7. Takebayashi Y, Natsugoe S, Baba M, Akiba S, Fukumoto T, Miyadera K, Yamada Y, Takao S, Akiyama S, Aikou T. Thymidine phosphorylase in human esophageal squamous cellcarcinoma,1999; Cancer 85: 282-289.

Conflito de interesse: não há Fonte financiadora: não há Recebido para publicação em: 17/06/2007 Aceito para publicação em: 23/10/2007 